\title{
First-in-human experience with the Cardia Ultraseal left atrial appendage closure device: The feasibility study
}

\author{
Robert Sabiniewicz ${ }^{1}$, Jarosław Hiczkiewicz ${ }^{2}$, Piotr Wańczura ${ }^{3}$, \\ Wojciech Stecko ${ }^{3}$, Andrzej Curzytek ${ }^{3}$

\begin{abstract}
${ }^{2}$ Department of Cardiology, Multidisciplinary District's Hospital, Nowa Sol, Poland
\end{abstract} \\ ${ }^{1}$ Department of Pediatric Cardiology and Congenital Heart Diseases, Medical University of Gdansk, Poland \\ ${ }^{3}$ Division of Cardiology, Independent Public Health Care Ministry of Internal Affairs, Rzeszow, Poland
}

\section{Introduction}

Atrial fibrillation (AF) remains the most common cardiac arrhythmia, affecting $3-5 \%$ of the population aged $65-75$ years. It is associated with substantial mortality and morbidity, particularly due to stroke. Over $90 \%$ of clinically apparent embolisms in $\mathrm{AF}$ originate from the left atrial appendage (LAA). Nowadays, oral anticoagulation still remains the state-of-the-art therapy for patients with AF. Since the first percutaneous LAA occlusion (LAAO) in 2002 [1] many studies have shown the safety and efficacy of this therapy using different closure devices [2-9]. Percutaneous LAAO is a valuable therapeutic option for selected high-risk patients with $\mathrm{AF}$ and contraindications for oral anticoagulation therapy. Currently, there are several types of devices available for LAAO: Watchman, ACP-Amplatzer Cardiac Plug, Coherex WaveCrest, and Cardia Ultraseal. These devices represent a variety of designs and thus offer uniquely different approaches to the mechanical closure of the LAA. The Cardia Ultraseal LAA closure device is a newly designed device, representing a novel concept of LAAO. Recently, first in vivo study demonstrated the feasibility and safety of Cardia device in the canine model [10]. Herein, we present first-in-human original experience with Cardia device.

The Cardia Ultraseal LAA device is a unique next generation design which combines the advantages of a distal anchoring bulb with the proven performance of a proximal sail to close the LAA orifice. These two

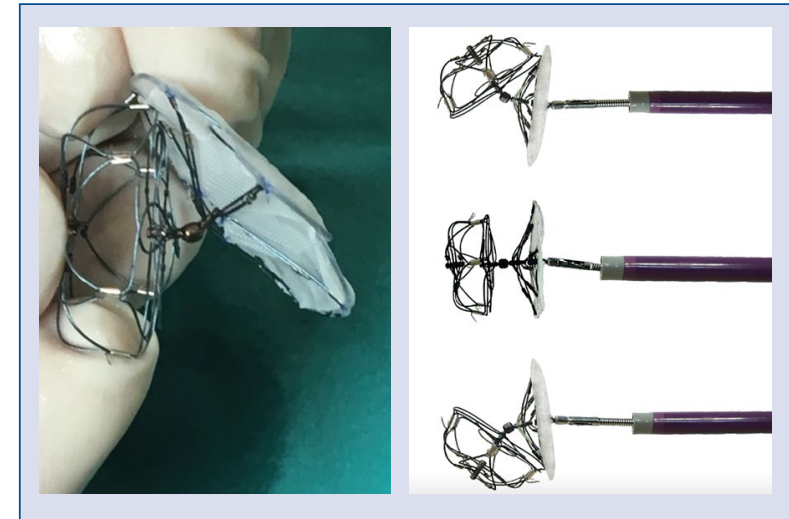

components are connected with a dual articulating joint allowing the device to conform naturally to the most tortuous of LAA anatomies. It is constructed with a nitinol frame and designed in a manner which produces a soft and flexible device. The combination of these characteristics provides an attractive design which easily conforms to the LAA and surrounding structures with minimal risk of residual shunt or anatomical distortion (Fig. 1A). The device is available in 9 different bulb sizes ranging from $16 \mathrm{~mm}$ to $34 \mathrm{~mm}$. The sail diameter is $6 \mathrm{~mm}$ larger than the distal bulb and delivery sheath sizes range from $10 \mathrm{Fr}$ to $12 \mathrm{Fr}$ (Fig. 1A, B).

\section{Sizing and device selection}

The LAA should be measured at a depth of $10-12 \mathrm{~mm}$ from the intended sail location. This rep-

Address for correspondence: Robert Sabiniewicz, MD, PhD, Department of Pediatric Cardiology and Congenital Heart Diseases, Medical University of Gdansk, ul. Dębinki 7, 80-211 Gdańsk, Poland, tel: +48 5834928 70, fax: +485834928 95, e-mail: sabini@gumed.edu.pl

Received: 07.08.2016 Accepted: 27.09.2016 


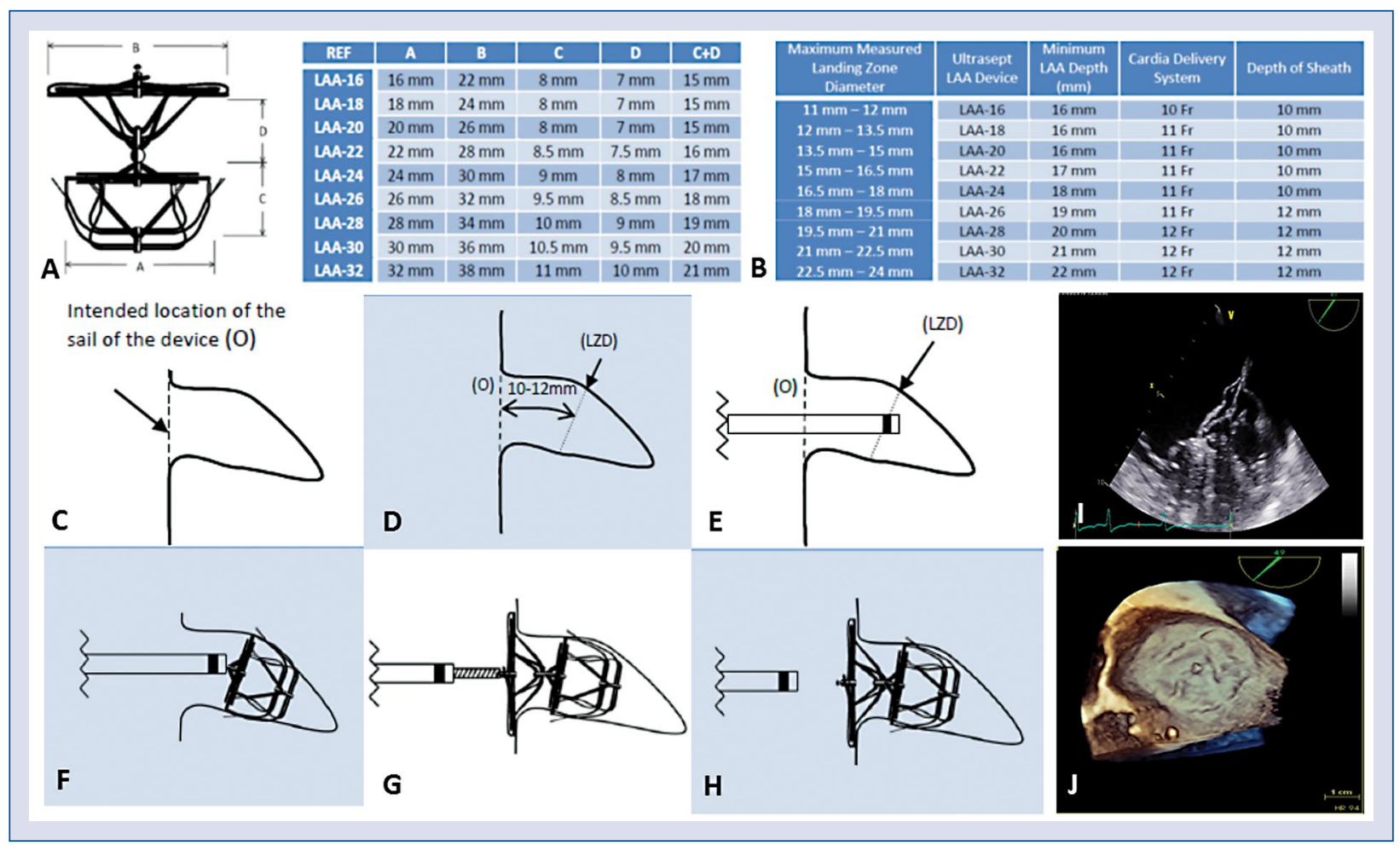

Figure 1. A. The Cardia Ultraseal left atrial appendage (LAA) device consists of proximal disc (to cover the LAA orifice) and a distal atraumatic soft lobe (to secure the device in the LAA) connected by a double articulating center for optimal positioning and repositioning within the appendage; 12 stabilizing anchors enabling secure engagement to the LAA; The discs (B) are $6 \mathrm{~mm}$ larger for lobe sizes $16 \mathrm{~mm}$ to $32 \mathrm{~mm}$ (A). B. The Cardia Ultraseal LAA device selection. C-H. Technique of implantation (C. Sizing the orifice of LAA; D. Landing zone - approximately 10-12 mm from the orifice; E. Positioning of the sheath; F. Positioning of the body of the device; G. Opening the sail of the device - the device is fully opened, but still connected with delivery system; H. Releasing of the device; LZD - landing zone diameter). I, J. The optimal position of Cardia Ultraseal LAA device in LAA of patient 4 documented in the two-dimensionaltransesophageal echocardiography (I) and three-dimensional-transesophageal echocardiography imaging (J).

resents the landing zone for the anchoring hooks of the device. The selected device should have a bulb diameter at least $25 \%$ to $33 \%$ greater than the largest diameter of the landing zone. The proximal pin of the device is grasped using the delivery forceps, then the device is pulled into the loader and flushed. The distal end of the sheath should be positioned in the LAA at the intended landing zone. Holding the sheath in place, the forceps are advanced until the entire bulb section of the device is deployed. The anchor markers of the bulb should appear to have a non-symmetric shape. This indicates that the bulb is properly under compression. The bulb should be kept in the same position and then the sheath is retracted until the entire sail section of the device is deployed. To confirm a stable position, a gentle pushing and pulling maneuver should be performed. Transesophageal echocardiography (TEE) should confirm the position of the device and the distance of the sail from other cardiac structures including mitral valve and pulmonary veins should be at least $5 \mathrm{~mm}$. If the position of the device and complete closure of LAA is confirmed in TEE, the device can be released. The device can easily be partially and/or fully retrieved and redeployed (maximum 5 times) before release (Fig. 1C-H).

\section{Methods and results}

Six patients aged $64-70$ (mean 72.8 ) years were selected for LAA closure. The primary indications for LAAO were gastrointestinal bleedings and nose bleedings. Mean HAS-BLED and $\mathrm{CHA}_{2} \mathrm{DS}_{2}$ VASC scale were 3.8. Mean LAA diameter was 20.8 (range 14.7-25) $\mathrm{mm}$ as measured by TEE and 20.5 (range 14.3-28) $\mathrm{mm}$ as measured by fluoroscopy. Patient data, indication for LAA closure, anatomy, and diameter of LAA are summarized in Table 1. 
Table 1. Patient data, indication for left atrial appendage (LAA) closure, anatomy and diameter of LAA, device selection, procedural parameters.

\begin{tabular}{lcccccccccccc}
\hline No. Sex & $\begin{array}{c}\text { Age } \\
\text { [years] }\end{array}$ & $\begin{array}{c}\text { Indication } \\
\text { for LAA } \\
\text { closure }\end{array}$ & & & $\begin{array}{c}\text { A } \\
\text { B }\end{array}$ & $\begin{array}{c}\text { Diameter } \\
\text { of LAA } \\
\text { Echo } \\
\text { [mm] }\end{array}$ & $\begin{array}{c}\text { Diameter } \\
\text { of LAA } \\
\text { Fluoro } \\
\text { [mm] }\end{array}$ & $\begin{array}{c}\text { Anatomy } \\
\text { of the } \\
\text { LAA }\end{array}$ & $\begin{array}{c}\text { LAA } \\
\text { device } \\
\text { size }\end{array}$ & $\begin{array}{c}\text { Fluoroscopy } \\
\text { time } \\
\text { [min] }\end{array}$ & $\begin{array}{c}\text { Procedure } \\
\text { time } \\
\text { [min] }\end{array}$ \\
\hline 1 & M & 79 & a & 4 & 3 & 14.7 & 14.6 & Cauliflower & 20 & 19.7 & 80 \\
2 & M & 78 & a & 5 & 6 & 23 & 14.3 & Windsock & $26 / 18$ & 23.8 & 100 \\
3 & M & 64 & b & 2 & 3 & 19 & 18.2 & Cactus & 24 & 34 & 45 \\
4 & M & 64 & a & 4 & 3 & 22 & 21.9 & Windsock & 26 & 16.9 & 60 \\
5 & F & 75 & c & 3 & 3 & 21 & 26 & Chicken- & 32 & 10.6 & 55 \\
6 & F & 77 & a & 5 & 5 & 25 & 28 & Windsock & 30 & 13.1 & 60 \\
Mean & 72.8 & & 3.8 & 3.8 & 20.8 & 20.5 & & & 19.7 & 65 \\
\hline
\end{tabular}

A - HAS-BLED scale; $\mathrm{B}-\mathrm{CHA}_{2} \mathrm{DS}_{2} \mathrm{VASC}$ scale; Indication for LAA closure: $a$ - gastrointestinal bleeding; $b$ - bleeding from the nose; $\mathrm{C}$ - bleeding hemorrhoids; Patient No. 2 - procedure abounded; $\mathrm{M}$ - male; $\mathrm{F}$ - female

Patients were catheterized and prepared for the LAA closure procedure utilizing standard techniques. The transseptal puncture was performed under TEE guidance. The delivery sheath was positioned within the LAA under fluoroscopic and TEE guidance. In 5 patients, the Cardia Ultraseal LAA device was implanted without any difficulty or technical problems. Procedure time was 58 (range 45-80) min and fluoroscopy time was 18.9 (range 19.7-34) min. The final position of all devices was correct, and there was no residual leak documented by TEE imaging (Fig. 1I, J). In 1 patient (No. 2), the anatomy of the LAA and surrounding structures were not suitable for device implantation and the procedure was discontinued. In the 1-month-follow-up TEE examination, the position of all devices was optimal. There was no thrombus formation, and no residual leak and all LAAs have been fully occluded.

In summary, the Cardia Ultraseal LAA closure device presents a new concept in LAAO procedures. The construction of the device is unique, and the device is easy to use and suitable for a broad spectrum of LAA anatomy. The dual articulating joint is very useful and allows superior positioning of the device in difficult angulated LAAs. Due to its soft construction and flexibility, the device fully adapts to the LAA anatomy and the sail easily conforms to the surrounding structures closing the LAA orifice with a very high rate of total occlusion. Our initial experience with this device included 5 implants with 30-day follow-up. An extensive clinical investigating is warranted to confirm the benefits of the Cardia Ultraseal LAA device and this new unique approach to close LAA.

\section{Conflict of interest: None declared}

\section{References}

1. Sievert H, Lesh MD, Trepels T. Percutaneous left atrial appendage transcatheter occlusion to prevent stroke in high-risk patients with atrial fibrillation: Early clinical experience. Circulation, 2002; 1056: 1887-18879.

2. Holmes DR, Reddy VY, Turi ZG et al. Percutaneous closure of the left atrial appendage versus warfarin therapy for prevention of stroke in patients with atrial fibrillation; a randomized noninferiority trial. Lancet, 2009; 374: 534-542.

3. Reddy VY, Holmes D, Doshi SK et al. Safety of percutaneous left atrial appendage closure: Results from the Watchman Left Atrial Appendage System for Embolic Protection in Patients with AF (PROTECT AF) clinical trial and Combined Access registry. Circulation, 2011;123: 417-424.

4. Reddy VY, Doshi SK, Sievert H et al. Percutaneous left atrial appendage closure for stroke prophylaxis in patients with atrial fibrillation: 2,3-year follow-up of the PROTECT AF (Watchman Left Atrial Appendage System for Embolic Protection in Patients with Atrial Fibrillation) trial. Circulation, 2013; 127: 720-729.

5. Holmes DR Jr, Kar S, Prices MJ et al. Prospective randomized evaluation of the Watchman Left Atrial Appendage Closure device in patients with atrial fibrillations versus long-term warfarin therapy: The PREVAIL trial. J Am Coll Cardiol, 2014; 64: $1-12$.

6. Reddy VY, Mobius-Winkler S, Miller MA et al. Left atrial appendage closure with the Watchman device in patients with contraindication for oral anticoagulation: The ASAP study (ASA Plavix Feasibility Study with Watchman left Atrial Appendage Closure Technology). J Am Coll Cardiol, 2013; 61: 2551-2556.

7. Neuzner J, Dietze T, Paliege R et al. Left atrial appendage closure with the Amplatzer ${ }^{\mathrm{TM}}$ Cardiac Plug: Rationale for a higher degree of device oversizing at implantation. Cardiol J, 2015; 22: 201-205.

8. Lam YY, Yip GW, Yu CM et al. Left atrial appendage closure with Amplatzer Cardiac Plug for stroke prevention in atrial fibrillation: Initial Asia-Pacific experience. Catheter Cardiovascular Interv, 2012; 79: 794-800.

9. Urena M, Rodes-Cabau J, Freixa X et al. Percutaneous left atrial appendage closure with Amplatzer Cardiac Plug device in patients with nonvalvular atrial fibrillation and contraindications to anticoagulation therapy. J Am Coll Cardiol, 2013; 62: 96-102.

10. Cheng Y, Conditt G, Yi G et al. First in vivo evaluation of a flexible self-apposing left atrial appendage closure device in the canine model. Catheter Cardiovasc Interv, 2015; 86: 173-181. 